\title{
Functions for Thermal Stress Calculation Near a Transient Heat Source on a Flat Surface
}

\author{
Stephen Jarvis, Jr., ${ }^{1}$ and Garney Hardy ${ }^{2}$
}

(June 7, 1966)

\begin{abstract}
When an initially unstressed elastic solid at uniform temperature is subject to a transient, locally two-dimensional heat flux on a flat surface, the two-dimensional total stress field near the wall is locally determined for short times and may be constructed from the functions described in this report; Fortran programs are available for their computation. In particular, maximum total stress and total stress fields for initially large heat fluxes are readily obtained for estimations of yield probability.
\end{abstract}

Key Words: Elastic stress, heat transfer, plane strain, thermal stress, yield stress.

\section{Introduction}

When heat is suddenly applied to or withdrawn from the surface of an elastic solid, large superficial stresses are set up which can cause surface damage when local elastic limits are exceeded. This occurs, for example, when hot or cold material is suddenly brought into contact with the solid surface. If the surface is reasonably flat and the initial heat flux distribution rapidly varying in one direction only (for example, near the perimeter of contact of the hot material mentioned above), the initial transient stresses near the wall are obtainable from plane strain theory.

In this report, plane strain theory is used to analyze the total stress field near the surface of a semi-infinite elastic solid during a short time interval during which a large two-dimensional heat flow occurs; formulae are presented for numerical evaluation of the stress for a class of heat flux pulses which may be approximated by a simple physically relevant form. Such a stress field is useful for estimating the probability and location of fracture from either maximum stressyield strength data or a more sophisticated probability theory.

We shall consider then a semi-infinite elastic solid occupying the region $y \geqslant 0$ which at time $t=0$ has vanishing stress components, $\sigma_{i j}=0$, and uniform temperature $T=0$. Cartesian coordinates $x$ and $z$ are taken to lie in the surface and a given outward heat flux $q(x, t)$ independent of $z$ is stipulated, so that the temperature $T(x, y, t)$, the stresses $\sigma_{i j}(x, y, t)$, the strains $\epsilon_{i j}(x, y, t)$, and the displacements $u_{i}(x, y, t),(i=1,2)$, do not depend on $z$. We assume also (plane strain) $u_{3}(x, y, t)=0$.
We shall neglect the heat generated in the solid by the strains, and assume that the temperature is governed by the heat equation

$$
T_{, t}=D(T, x x+T, y y),
$$

where $D$ is the coefficient of thermal diffusion. We shall also neglect the inertial effects in the solid, assuming that the stress is quasi-stationary near the surface. Then

$$
\sigma_{i j . j}=0, \quad(i, j=1,2,3),
$$

where the stress-stain relation $[1]^{3}$ is given by

$$
\sigma_{i j}=\lambda \delta_{i j} \epsilon_{k k}+2 \mu \epsilon_{i j}-m T \delta_{i j}
$$

the strains are given in terms of the displacements by:

$$
\epsilon_{i j}=\frac{1}{2}\left(u_{i, j}+u_{j, i}\right), \quad(i, j=1,2,3) .
$$

Here $\lambda$ and $\mu$ are the Lame constants, $\alpha$ is the coefficient of linear thermal expansion, and $m=\alpha(3 \lambda+2 \mu)$. The Lame constants $\lambda$ and $\mu$ are given in terms of the Young's modulus $E$ and Poisson's ratio $\nu$ as follows [1]:

$$
\lambda=\frac{\nu E}{(1+\nu)(1-2 \nu)}, \quad \mu=\frac{E}{2(1+\nu)} .
$$

The validity of the assumptions made in the above equations will depend on the specific heat flux involved, $q(x, t)$, and the region being studied, and should be checked a posteriori.

We shall assume further that a single scalar, the total stress (the first stress invariant),

$$
\sigma \equiv \sigma_{i i}=\sigma_{11}+\sigma_{22}+\sigma_{33}
$$

${ }^{1}$ Institute for Basic Standards, Radio Standards Laboratory, National Bureau of Standards, Boulder, Colo.

${ }^{2}$ Environmental Science Services Administration, IER, Boulder, Colo.

${ }^{3}$ Figures in brackets indicate the literature references on page 270. 
suffices for yield analysis. Yield criteria may be based on extreme values of $\sigma$ or on the more sophisticated probability theories using the stress distribution $[2,3]$.

Boundary conditions on the stress system are that surface forces vanish on $y=0$ :

$$
\sigma_{12}=\sigma_{22}=0, \quad \text { on } y=0 .
$$

It is well known [4] that when two bodies at different temperatures are put in contact at $t=0$, heat is transferred at a rate $0\left(t^{-1 / 2}\right)$ for sufficiently short times. We shall assume the heat flux time history in a time interval of interest, $0 \leqslant t \leqslant t_{F}$, is approximated as follows:

$$
q(x, t)=\sum_{n=0}^{3} A_{n}(x) t^{n-1 / 2}, \quad\left(0 \leqslant t \leqslant t_{F}\right) .
$$

In particular, we shall find the total stress fields $\sigma_{n \delta}(x, y, t)$ associated with the line source heat fluxes:

$$
q_{n \delta}(x, t)=\delta(x) t^{n-1 / 2}, \quad(n=0,1,2,3) .
$$

Then the stress $\sigma(x, y, t)$ for the general heat flux of (7) is given by

$$
\sigma(x, y, t)=\sum_{n=0}^{3} \int_{-\infty}^{\infty} d s A_{n}(s) \sigma_{n \delta}(x-s, y, t) .
$$

Our principal task is to construct the functions $\sigma_{n \delta}(x, y, t)$.

\section{Analytic Evaluation of the Stress $\sigma_{n \delta}(x, y, t)$}

For the case of plane strain, the strains and stresses are given in terms of the displacements as follows:

$$
\begin{aligned}
& \left\{\begin{array}{l}
\epsilon_{11}=u_{1, x} \\
\epsilon_{12}=\epsilon_{21}=\frac{1}{2}\left(u_{1, y}+u_{2, x}\right) \\
\epsilon_{22}=y_{2, y} \\
\epsilon_{i 3}=\epsilon_{3 i}=0 \quad(i=1,2,3) \\
\epsilon_{i i}=u_{1, x}+u_{2, y}
\end{array}\right. \\
& \left\{\begin{array}{l}
\sigma_{11}=\lambda \epsilon_{i i}+2 \mu u_{1, x}-m T \\
\sigma_{12}=\sigma_{21}=\mu\left(u_{1, y}+u_{2, x}\right) \\
\sigma_{22}=\lambda \epsilon_{i i}+2 \mu u_{2, y}-m T \\
\sigma_{33}=\lambda \epsilon_{i i}-m T \\
\sigma_{23}=\sigma_{32}=\sigma_{13}=\sigma_{31}=0 \\
\sigma=\sigma_{i i}=(3 \lambda+2 \mu) \epsilon_{i i}-3 m T .
\end{array}\right.
\end{aligned}
$$

The equations (2) become:

$(\lambda+2 \mu) u_{1, x x}+\lambda u_{2, x y}-m T,{ }_{x}+\mu\left(u_{1, y y}+u_{2, x y}\right)=0$

$(\lambda+2 \mu) u_{2, y y}+\lambda u_{1, x y}-m T,_{y}+\mu\left(u_{1, x y}+u_{2, x x}\right)=0$.

For a function $f(x, y, t)$, satisfying appropriate conditions, we introduce the Laplace transform $\mathscr{L}$ in $t$ and the Fourier transform $\mathscr{F}$ in $x$ :

$F(y ; k, s) \equiv \mathscr{F} \mathscr{L} f(x, y, t)$

$$
=\frac{1}{\sqrt{2 \pi}} \int_{-\infty}^{\infty} d x e^{-i k x} \int_{0}^{\infty} d t e^{-s t} f(x, y, t)
$$

with the inverse:

$$
\begin{aligned}
& f(x, y, t)=\mathscr{F}^{-1} \mathscr{L}^{-1} F(y ; k, s) \\
&=\frac{1}{\sqrt{2 \pi}} \int_{-\infty}^{\infty} d k e^{i k x} \\
& \cdot \frac{1}{2 \pi i} \int_{c-i \infty}^{c+i \infty} d s e^{s t} F(y ; k, s) .
\end{aligned}
$$

The transforms of $\left(u_{1}, u_{2}, T, \sigma\right)$ are denoted, respectively, by $(U, V, \Theta, \Sigma)$.

We obtain the system of ordinary differential equations:

$$
\left\{\begin{array}{l}
\left(s+k^{2} D\right) \Theta-D \Theta, y y=0 \\
-(\lambda+2 \mu) k^{2} U+\mu U, y y+(\lambda+\mu) i k V, y-i k m \Theta=0 \\
-\mu k^{2} V+(\lambda+2 \mu) V,{ }_{y y}+(\lambda+\mu) i k U,{ }_{y}-m \Theta,{ }_{y}=0 .
\end{array}\right.
$$

Boundary conditions are boundedness of the transforms as $y \rightarrow \infty$, and the following conditions at $y=0$ follow from (6):

$$
U,{ }_{y}+i k V=0, \quad i k \lambda U+(\lambda+2 \mu) V,{ }_{y}-m \Theta=0,
$$

and by (8) at $y=0$ :

$$
K \Theta,{ }_{y}=\frac{1}{\sqrt{2 \pi}} \frac{\Gamma\left(n+\frac{1}{2}\right)}{s^{n+1 / 2}},
$$

where $K$ is the coefflcient of heat conduction. The system of (15) has solutions of the form

$$
\left(\begin{array}{c}
\Theta \\
U \\
V
\end{array}\right)=\left(\begin{array}{c}
\theta_{1} \\
U_{1} \\
V_{1}
\end{array}\right) e^{-\nu_{1} y}+\left(\begin{array}{l}
0 \\
U_{2}+y U_{3} \\
V_{2}+y V_{3}
\end{array}\right) e^{-k y \epsilon},
$$


where:

$$
\begin{aligned}
\nu_{1} & =\left(k^{2}+\frac{s}{D}\right)^{1 / 2}, \\
\epsilon & =\operatorname{sgn} k,
\end{aligned}
$$

and $\nu_{1}$ has nonnegative real part. Substitution of (17) into (15) and use of the conditions (16.1) gives the following:

$$
\left\{\begin{array}{l}
U=\left[q_{11} e^{-\nu_{1} y}+\left(q_{12}+y q_{13}\right) e^{-1 k \cdot y}\right] \Theta_{1} \\
V=\left[q_{21} e^{-\nu_{1} y}+\left(q_{22}+y q_{23}\right) e^{-1 k l y}\right] \Theta_{1}
\end{array}\right.
$$

where:

$q_{11}=\frac{i k m D}{(\lambda+2 \mu) s}$,

$$
q_{21}=-\frac{\nu_{1} m D}{(\lambda+2 \mu) s}
$$

$q_{12}=\frac{m D}{2 i k s(\lambda+\mu)(\lambda+2 \mu)}\left\{2 \epsilon(\lambda+2 \mu) k \nu_{1}-2 \mu k^{2}\right\}$,

$$
q_{13}=\frac{i m D}{2 \mu s(\lambda+2 \mu)}\left\{2 \mu k \nu_{1}-2 \mu k^{2} \epsilon\right\}
$$

$q_{22}=\frac{m D}{2 k \mu s(\lambda+\mu)(\lambda+2 \mu)}\left\{-2 \mu^{2} k \nu_{1}+2 \mu(\lambda+2 \mu) k^{2} \boldsymbol{\epsilon}\right\}$,

$q_{23}=i \epsilon q_{13}$

The stress transform $\Sigma$ is readily found to contain no term linear in $y$ :

$$
\sum=\left[\alpha_{1} e^{-\nu_{1} y}+\left(\alpha_{2} \frac{\nu_{1}|k|}{s}+\alpha_{3} \frac{k^{2}}{s}\right) e^{-|k| y}\right] \Theta_{1}
$$

where the $\alpha_{i}$ do not depend on $(k, s, y)$ :

$$
\begin{aligned}
& \alpha_{1}=-\frac{4 \mu m}{\lambda+2 \mu} \\
& \alpha_{2}=-\alpha_{3}=\frac{2 \mu m D(3 \lambda+2 \mu)}{(\lambda+\mu)(\lambda+2 \mu)} .
\end{aligned}
$$

We notice that the first term on the right-hand side of (21) gives a term directly proportional to the temperature (17). By (16.2) and (17),

$$
\Theta_{1}=-\frac{1}{K \sqrt{2 \pi}} \frac{\Gamma\left(n+\frac{1}{2}\right)}{\nu_{1} s^{n+1 / 2}} \text {. }
$$

Inverse transforms of the terms in (21) may be obtained by manipulation of tabulated transforms. It is convenient to introduce the variables:

$$
\begin{gathered}
r=\sqrt{x^{2}+y^{2}}, \quad(\xi, \eta, \rho)=\frac{(x, y, r)}{\sqrt{4 D t}}, \\
\varphi=\tan ^{-1} \frac{\xi}{\eta}, \quad z=\rho^{2} e^{-2 i \varphi}, \quad|\arg z| \leqslant \pi .
\end{gathered}
$$

Then for the first of the terms in (21), we note [5a]:

$$
\begin{aligned}
& \mathscr{L}^{-1 \mathscr{F}-1}\left(e^{-\nu_{1} y} / \nu_{1} s^{n+1 / 2}\right) \\
& =\frac{1}{\sqrt{2 \pi}} t^{n-1 / 2} e^{-|z|} \psi\left(\frac{1}{2}+n, 1 ;|z|\right),
\end{aligned}
$$

where we have made use of the relation between the Whittaker function $W_{-n, 0}(z)$ and the confluent hypergeometric $[6 \mathrm{a}]$ function $\psi\left(\frac{1}{2}+n, 1 ; z\right)$.

$$
\mathscr{L}^{-1} \mathscr{F}-1 \frac{|k| e^{-|k| y}}{s^{n+3 / 2}}=\frac{1}{\sqrt{2 \pi D}} \frac{t^{n-1 / 2}}{\Gamma\left(n+\frac{3}{2}\right)} \frac{\cos 2 \varphi}{|z|}
$$

For the third term of (2l) we note that

$$
\mathscr{L}^{-1} \mathscr{F}-1 \frac{k^{2} e^{-|k| y}}{\nu_{1} s^{n+3 / 2}}=\sqrt{\frac{2}{\pi}} \frac{\partial^{2}}{\partial y^{2}} I_{n}(x, y, t),
$$

where:

$$
\begin{gathered}
I_{n}(x, y, t) \equiv \mathscr{L}^{-1} \frac{1}{s^{n+3 / 2}} J(x, y, s), \\
J(x, y, s) \equiv \int_{0}^{\infty}: d k \frac{\cos k x \cdot e^{-k y}}{\sqrt{k^{2}+\frac{s}{D}}} .
\end{gathered}
$$

Then in terms of Struve's function $\mathbf{H}_{0}(z)$ and Bessel's function [5c] of the second kind $Y_{0}(z)$,

$$
\begin{aligned}
J(x, y, s) & =\frac{\pi}{4}\left[\mathbf{H}_{0}\left(r e^{-i \varphi} \sqrt{\frac{s}{D}}\right)-Y_{0}\left(r e^{-i \varphi} \sqrt{\frac{s}{D}}\right)\right] \\
& +\frac{\pi}{4}\left[\mathbf{H}_{0}\left(r e^{i \varphi} \sqrt{\frac{s}{D}}\right)-Y_{0}\left(r e^{i \varphi} \sqrt{\frac{s}{D}}\right)\right] .
\end{aligned}
$$

Then $[5 \mathrm{~d}, 6 \mathrm{~b}]$,

$$
\begin{aligned}
& I_{-1}(x, y, t)=\frac{1}{2 \sqrt{\pi t}} \text { Real }\left\{e^{z / 2} K_{0}\left(\frac{z}{2}\right)\right\} \\
&=\frac{1}{2 \sqrt{t}} \text { Real }\left\{\psi\left(\frac{1}{2}, 1 ; z\right)\right\},
\end{aligned}
$$

where $K_{0}$ is the modified Bessel function of the second 
kind. It follows that [5e]:

$$
\begin{aligned}
I_{n}(x, y, t)= & \left(\int_{0}^{t} d t \cdot\right)^{n+1} I_{-1}(x, y, t) \\
= & \frac{1}{2}(-)^{n+1}\left(\frac{r^{2}}{4 D}\right)^{n+1 / 2} \text { Real }\left\{e^{-i \varphi(2 n+1)}\right. \\
& \left.\cdot\left(\int_{\infty}^{z} \frac{d z}{z^{2}}\right)^{n+1} z^{1 / 2} \psi\left(\frac{1}{2}, 1 ; z\right)\right\}
\end{aligned}
$$

where $\left(\int d t \cdot\right)^{n+1}$ is the $(n+1)$-th iterated integral. Each integral is independent of the argument of the lower limit for $z$ if $|\arg z|<3 \pi / 2$. It is easy to establish by recursion the following formula [6e]:

$$
\begin{aligned}
\left(\int_{-\infty}^{z} \frac{d z}{z^{2}} \cdot\right)^{n+1} z^{1 / 2} \psi & \left(\frac{1}{2}, 1 ; z\right)=\frac{C_{n}^{*}}{z^{n+1 / 2}} \psi\left(-n-\frac{1}{2}, 1 ; z\right) \\
& -\sum_{K=0}^{n} \frac{(-)^{K}}{z^{K}} \frac{C_{n-K}^{*}}{K !}, C_{n}^{*} \equiv\left[\frac{\pi}{\Gamma\left(n+\frac{3}{2}\right)}\right]^{2}
\end{aligned}
$$

The finite sum removes from the first term of the right-hand side those terms of the asymptotic series which would give a nonvanishing result as $z \rightarrow \infty[6 \mathrm{~d}]$.

We introduce the following real-valued functions:

$$
\begin{aligned}
& G_{1 n}(\xi, \eta)=\operatorname{Real}\left\{\psi\left(\frac{1}{2}-n, 1 ; z\right)\right\} \\
& G_{2 n}(\xi, \eta)=\operatorname{Real}\left\{\left(4 n^{2}-1\right) z \psi\left(\frac{3}{2}-n, 3 ; z\right)\right. \\
& \left.\quad+(2 n+1) \psi\left(\frac{1}{2}-n, 2 ; z\right)\right\}
\end{aligned}
$$

Finally then we are able to write the total stress as follows:

$$
\sigma_{n \delta}(x, y, t)=\frac{m}{K} t^{n-1 / 2}\left\{\Lambda_{1} f_{n}(\xi, \eta)+\Lambda_{2} h_{n}(\xi, \eta)\right\}
$$

where the functions $\left(f_{n}, h_{n}\right)$ are even in $\xi$ and do not depend on the material parameters:

$$
\begin{aligned}
& f_{n}(\xi, \eta)=-\frac{1}{\pi} \frac{2}{2 n+1} \frac{\cos 2 \varphi}{\rho^{2}}+\frac{(-)^{n+1}}{(2 n+1) \Gamma\left(n+\frac{3}{2}\right)} \\
& \cdot\left\{G_{2 n}(\xi, \eta)-\sum_{K=0}^{n} \frac{(-)^{K}}{K !}\left\lfloor\frac{\Gamma\left(n+\frac{3}{2}\right)}{\Gamma\left(n-K+\frac{3}{2}\right)}\right]^{2}\right. \\
&\left.\cdot(2 n+1-2 K)(2 n-2 K) \rho^{2 n-1-2 K} \cos \varphi(2 n-1-2 k)\right\},
\end{aligned}
$$

$$
h_{n}(\xi, \eta)=\frac{\Gamma\left(n+\frac{1}{2}\right)}{\pi} e^{-\rho^{2}} \psi\left(n+\frac{1}{2}, 1 ; \rho^{2}\right) .
$$

The constants $\Lambda_{i}$ in (34) are the following:

$$
\begin{aligned}
& \Lambda_{1}=\frac{\mu(3 \lambda+2 \mu)}{2(\lambda+\mu)(\lambda+2 \mu)}, \\
& \Lambda_{2}=\frac{2 \mu}{(\lambda+2 \mu)} .
\end{aligned}
$$

We note the useful relation:

$$
T_{n \delta}(x, y, t)=-\frac{1}{2 K} t^{n-1 / 2} h_{n}(\xi, \eta),
$$

giving the temperature field in the solid due to the line heat source of (8).

\section{Numerical Evaluation of $\left(f_{n}, h_{n}\right)$}

Expressions are given in appendix $\mathbf{A}$ for the interim functions $G_{1 n}(\xi, \eta), G_{2 n}(\xi, \eta)$, both convergent and asymptotic series. Using double precision computation (25 digit mantissa) for the convergent series, single precision computation (10 digit mantissa, exponent less than 308) for the asymptotic series, agreement between the two was to six significant figures at $\rho^{2}=20$ for several values of $\varphi$ on $0 \leqslant \varphi \leqslant \frac{\pi}{2}$, and thus $\rho=\sqrt{20}$ was taken as the crossover point.

Expressions for $h_{n}(\xi, \eta)$ are also given in appendix A in terms of the functions $G_{1 n}(0, \rho)$ using a recursion relation.

As $\rho \rightarrow 0$, the $G_{2 n}$ have integrable singularities:

$$
\begin{gathered}
f_{n} \rightarrow \frac{1}{\pi}\left\{\ln \rho^{2}+\left(\psi\left(\frac{1}{2}-n\right)-\psi(1)-\psi(2)+2\right)+0(\rho)\right\}, \\
h_{n} \rightarrow-\frac{1}{\pi}\left\{\ln \rho^{2}+\left(\psi\left(\frac{1}{2}+n\right)-2 \psi(1)\right)+0(\rho)\right\}
\end{gathered}
$$

where $0(\rho)$ vanishes as $\rho \rightarrow 0$, and $\psi(x)$ is the Digamma function [7]. We may then integrate $\sigma_{n \delta}$ over $y=0$ as required in the convolution (9).

For large $\rho$, the simple forms,

$$
\begin{gathered}
f_{n} \sim-\frac{1}{\pi} \frac{2}{2 n+1} \frac{\cos 2 \varphi}{\rho^{2}}+\frac{}{\pi \Gamma(n+2)} \frac{\Gamma\left(n+\frac{1}{2}\right)}{\rho^{3}}+0\left(\rho^{-5}\right), \\
h_{n} \sim 0,
\end{gathered}
$$

give better than one percent accuracy for $\rho \geqslant 10$. These formulae show that 


$$
\sigma_{n \delta} \widetilde{\rho}\left[\frac{m \Lambda_{2}}{\mathrm{~K}} \frac{\Gamma\left(n+\frac{1}{2}\right) \sqrt{4 D}}{\pi \Gamma(n+1)}\right] \cdot \frac{t^{n} y}{x^{2}+y^{2}},
$$

so that for short times $(r / \sqrt{4 D t} \rightarrow \infty)$, the stress field of a line source dies off $0\left(1 / x^{2}\right)$ for $|x| \gg y$ (although only $0(1 / y)$ for $y \gg|x|)$. This integrable decay rate in $x$ makes the convolution (9) useful since the large stresses expected near the surface at early times are locally induced, and the plane stress theory is applicable in more general situations.

A subroutine for the calculation of $\left\{G_{1 n}(\xi, \eta)\right.$, $\left.G_{2 n}(\xi, \eta)\right\}$, and a program employing this subroutine for the calculation of $\left\{f_{n}(\xi, \eta), h_{n}(\xi, \eta)\right\}$ for a given value of $\eta$ on the set of values,

$$
\xi=0.0(0.1) 10.0
$$

is discussed in appendix B. The calculated values are stored on tape in consecutive values of $\xi$ in the following order for each $\xi$ :

$\left\{f_{0}(\xi, \eta), \ldots, f_{3}(\xi, \eta), h_{0}(\xi, \eta), \ldots, h_{3}(\xi, \eta)\right\}$.

The values are sufficiently slowly varying that Simpson's rule integration in (9) is normally adequate. Calculation of these functions on the set (41) for a given value of $\eta$ takes on the average about two minutes, and was done for the set of integer values

$$
\eta=0.0(1.0) 10.0 \text {. }
$$

These data are now on magnetic tape, and are available on punched cards. (The singular values $(\xi=0, \eta=0)$ have been replaced by the values at $(\xi=0.1, \eta=0)$ as being adequate for integration.)

\section{Step-Input Stress Response}

A special case of heat flux of particular interest for stress evaluation near the perimeter of an (almost) uniform source is obtained from the general source of (7) by setting

$$
A^{n}(x)=A_{n} h(x),
$$

where the $A_{n}$ are constants and

$$
h(x)= \begin{cases}0 & (x<0) \\ 1 & (x \geqslant 0)\end{cases}
$$

Then the resulting stress $\sigma_{h}$ is found by (9) to be

$$
\begin{aligned}
\sigma_{h}(x, y, t)=\frac{m \sqrt{4 D}}{\mathrm{~K}} \sum_{n=0}^{3} A_{n} t^{n}\{ & \Lambda_{1} F_{n}(\xi, \eta) \\
& \left.+\Lambda_{3} H_{n}(\xi, \eta)\right\},
\end{aligned}
$$

where:

$$
\begin{gathered}
\left(\begin{array}{l}
F_{n} \\
H_{n}
\end{array}\right) \equiv \int_{-\infty}^{\xi} d s\left(\begin{array}{l}
f_{n}(|s|, \eta) \\
h_{n}(|s|, \eta)
\end{array}\right), \\
(\xi, \eta)=\frac{(x, y)}{\sqrt{4 D t}}
\end{gathered}
$$

When the entire path of integration $\left(\xi_{1}, \xi_{2}\right)$ lies outside the circle of radius $\rho=10$, the asymptotic forms (39) are used to evaluate:

$$
\phi_{n}\left(\xi_{2}, \xi_{1} ; \eta\right)=\int_{\xi_{1}}^{\xi_{2}} d s f_{n}(|s|, \eta)
$$

each term of (39) having a simple closed-form integral. Then for $0 \leqslant \eta \leqslant 10$, we have

$\xi \leqslant-10 .:$

$$
\left(\begin{array}{c}
F_{n}(\xi, \eta) \\
H_{n}(\xi, \eta)
\end{array}\right)=\left(\begin{array}{c}
\phi_{n}(\xi,-\infty ; \eta) \\
0
\end{array}\right)
$$

$-10 . \leqslant \xi \leqslant 10 .:$

$$
\left(\begin{array}{l}
F_{n}(\xi, \eta) \\
H_{n}(\xi, \eta)
\end{array}\right)=\left(\begin{array}{c}
F_{n}(-10, \eta) \\
0
\end{array}\right)+\int_{-10}^{\xi} d s\left(\begin{array}{l}
f_{n}(|s|, \eta) \\
h_{n}(|s|, \eta)
\end{array}\right)
$$

$\xi \geqslant 10$.

$$
\left(\begin{array}{l}
F_{n}(\xi, \eta) \\
H_{n}(\xi, \eta)
\end{array}\right)=\left(\begin{array}{l}
F_{n}(10, \eta) \\
H_{n}(10, \eta)
\end{array}\right)+\left(\begin{array}{c}
\phi_{n}(\xi, 10 ; \eta) \\
0
\end{array}\right) .
$$

for $\eta>10$, (49) is valid for all $\xi$.

Appendix $\mathrm{C}$ describes a program for determining $\left\{F_{n}, H_{n}\right\}$ for given $\eta$, (one of the set (43) of course) on the set

$$
\xi=10 .(0.2) 20
$$

using Simpson's rule for the evaluation of the integrals in (50). These results are on magnetic tape and are available on punched cards. Calculations took about one-half minute for each value of $\eta$.

When $A_{0}=1, A_{1}=A_{2}=A_{3}=0$, the total stress field is self-similar in time, dependent $\xi$ and $\eta$ only, and rises monotonically (dominated by $G_{n}(\xi, \eta)$ ) in $\xi$ to a maximum value at $\xi=\infty$ independent of $\eta$. This value is attained at $(\eta=0, \xi=10)$. to the accuracy of the calculation, and may be determined from the values

$$
\left(\begin{array}{l}
F_{0}(20,0) \\
H_{0}(20,0)
\end{array}\right)=\left(\begin{array}{c}
-0.0637 \\
1.7724
\end{array}\right)
$$


For large values of $\xi$, the stress field $\sigma_{h}$ given by (46) is uniform in $x$ for any coefficient set $\left\{A_{n}\right\}$, and agree with the results for heat flux $q(t)$ uniform in $x$ described in appendix D.

\section{Conclusions}

Formulae are presented for the estimation of total stress fields near the surface of a solid during a short time interval during which a large heat transfer occurs. Such a stress field is useful for estimating the probability and location of fracture, either from maximum stress-yield strength data or from a more sophisticated probability theory. The stress fields obtained may be expected to be valid in a region adjacent to a point on the solid surface of dimension $l \approx \sqrt{4 D t}$ and for the time interval $0 \leqslant t \leqslant t_{F}$, the period of validity of the heat flux approximation (7), so long as the following orders hold:

$$
\sqrt{4 D t} \ll\left\{L, R_{m}, R_{q}\right\},
$$

where $L$ is a length scale for the solid, and $R_{m}$ and $R_{q}$ are, respectively, the mean radius of curvature of the solid surface and the radius of curvature of lines of constant outward heat flux at the point in question.

It would be desirable to have a "maximum principle" available, stating, for example, that if $q(x, t)=0$ for $t>t_{F}$, then the maximum value of $\sigma(x, y, t)$ over $(x, y)$ for any $t>t_{F}$ does not exceed the maximum value of $\sigma\left(x, y, t_{F}\right)$ over $(x, y)$. The part of the stress associated with $h_{n}(\xi, \eta)$ shares with the temperature field given by (37) such a maximum principle, but no more general result appears available.

The authors thank Robert Arnett of the Boulder Laboratories, National Bureau of Standards, for suggesting the problem and for many valuable comments.

\section{References}

[1] B. A. Boley and J. H. Weiner, Theory of Thermal Stresses (John Wiley \& Sons, New York, N.Y., 1960).

[2] W. Weibull, A Statistical Theory of the Strength of Materials, Proc. Royal Swedish Inst. Eng. Res., 151 (1939).

[3] J. Tucker, Jr., Statistical Theory of the Effect of Divisions and Method of Loading Upon the Modulus of Rupture of Beams, Proc. ASTM, 41, pp. 1072-1094 (1941).

[4] H. S. Carslaw and J. C. Jaeger, Conduction of Heat in Solids, 2d edition (Oxford, Clarendon Press, 1959).

[5] A. Erdelyi, Tables of Integral Transforms V. 1, Bateman Manuscript Project (McGraw-Hill Book Co.. Inc., New York, N.Y., 1954); (a) p. 283, \#43; (b) p. 15, \#7; (c) p. 138, \#10; (d) p. 287, \#14 (\#12 is in error); (e) p. 130, \#9.

[6] A. Erdelyi, Higher Transcendental Functions, V. 1, Bateman Manuscript Project (McGraw-Hill Book Co., Inc., New York, N.Y., 1953); (a) p. 264, 6.9(2); (b) p. 265, 6.9.1(13); (c) p. 261, 6.7.1(13); (d) p. 278, 6.13.1(1); (e) p. 258, 6.6(13).

[7] M. Abramowitz and L. A. Stegun, Handbook of Mathematical Functions, AMS 55, p. 258, National Bureau of Standards (1964).

\section{Appendix A. The Functions $\left\{G_{1 n}(\xi, \eta)\right.$, $\left.G_{2 n}(\xi, \eta), h_{n}(\xi, \eta)\right\}$}

The following expansions for $G_{1 n}, G_{2 n}$ are readily obtained from the definitions of (33) and the properties $[6 \mathrm{c}]$ of the confluent hypergeometric functions $\psi(a, b ; z)$ :

$$
\begin{aligned}
& G_{1 n}(\xi, \eta)= \frac{-1}{\Gamma\left(\frac{1}{2}-n\right)}\left\{\sum_{r=0}^{\infty} \frac{1}{(r !)^{2}} \frac{\Gamma\left(\frac{1}{2}-n+r\right)}{\Gamma\left(\frac{1}{2}-n\right)}\right. \\
& \cdot \rho^{2 r}\left[\left(\ln \rho^{2}\right) \cos 2 r \varphi-2 \varphi \sin 2 r \varphi\right] \\
&+\sum_{r=0}^{\infty} \frac{\Gamma\left(\frac{1}{2}-n-r\right)}{\Gamma\left(\frac{1}{2}-n\right)} \frac{1}{(r !)^{2}}\left[\psi\left(\frac{1}{2}-n+r\right)-2 \psi(1+r)\right]
\end{aligned}
$$

$$
\begin{array}{r}
\left.\cdot \rho^{2 r} \cos 2 r \varphi\right\}, \\
G_{1 n}(\xi, \eta) \widetilde{\rho} \sum_{m=0}^{\infty}(-)^{m} \frac{\rho^{2 n-1-2 m}}{m !} \cos \varphi(2 n-1-2 m) \\
\cdot\left[\frac{\Gamma\left(m+\frac{1}{2}-n\right)}{\Gamma\left(\frac{1}{2}-n\right)}\right]^{2},\left(|\varphi| \leqslant \frac{\pi}{2}\right) .
\end{array}
$$

$$
\begin{aligned}
& G_{2 n}(\xi, \eta)=\frac{(-)^{n+1}}{\pi} \Gamma\left(n+\frac{3}{2}\right)\left\{(2 n+1) \ln \rho^{2}\right. \\
& \quad+(1+2 n)\left(\psi\left(\frac{1}{2}-n\right)-\psi(1)-\psi(2)+2\right)+\frac{2 \cos 2 \varphi}{\rho^{2}}
\end{aligned}
$$

$$
\begin{gathered}
+(1+2 n) \sum_{l=1}^{\infty} \frac{(1+2 l)}{l !} \frac{\Gamma\left(\frac{1}{2}-n+l\right)}{\Gamma\left(\frac{1}{2}-n\right) \Gamma(l+2)} \rho^{2 l} \\
\cdot\left[\left(\ln \rho^{2}\right) \cos 2 l \varphi-2 \varphi \sin 2 l \varphi\right] \\
+(1+2 n) \sum_{l=1}^{\infty} \frac{\Gamma\left(\frac{1}{2}-n+l\right)}{l ! \Gamma(l+2) \Gamma\left(\frac{1}{2}-n\right)} \cdot[2+(2 l+1) \\
\left.\left.\cdot\left(\psi\left(\frac{1}{2}-n+l\right)-\psi(1+l)-\psi(2+l)\right)\right] \rho^{2 l} \cos 2 l \varphi\right\},
\end{gathered}
$$




$$
G_{2 n}(\xi, \eta) \widetilde{\rho} \sum_{m=0}^{\infty} \frac{(-)^{m}}{m !}\left[\frac{\Gamma\left(-\frac{1}{2}-n+m\right)}{\Gamma\left(-\frac{1}{2}-n\right)}\right]^{2}
$$

$(2 n+1-2 m)(2 n-2 m) \cdot \rho^{2 n-1-2 m} \cos \varphi(2 n-1-2 m)$,

$$
\left(|\varphi| \leqslant \frac{\pi}{2}\right)
$$

Let

$h_{n}^{*}(\xi, \eta) \equiv \frac{\Gamma\left(n+\frac{1}{2}\right)}{\pi} e^{-\rho^{2} G_{1 n}(0, \rho),}$

$$
(n=1,2) \text {. }
$$

Then $h_{n}(\xi, \eta)$ are found from the following expressions:

$h_{0}=h_{0}^{*}$,

$h_{1}=2 \rho^{2} h_{0}^{*}-4 h_{1}^{*}$,

$h_{2}=\frac{1}{3}\left[4 \rho^{2}\left(2+\rho^{2}\right)-1\right] h_{0}^{*}$

$$
-\frac{8}{3}\left(2+\rho^{2}\right) h_{1}^{*}
$$

$h_{3}=\frac{3}{10}\left\{\left[\frac{4}{9}\left(4+\rho^{2}\right)\left(4 \rho^{2}\left(2+\rho^{2}\right)-1\right)-4 \rho^{2}\right] h_{0}^{*}\right.$

$$
-8\left[\frac{4}{9}\left(4+\rho^{2}\right)\left(2+\rho^{2}\right)-1\right] h_{1}^{*} .
$$

\section{Appendix B. Description and Use of Fortran Programs for Calculation of $\left\{f_{n}, h_{n}\right\}$}

From the expansions for $G_{1 n}$ and $G_{2 n}$, given in appendix $A$, it can be seen that there are multiplicative factors in the sums which are dependent only on $n$ and the index of summation. These factors were therefore computed using the program GCOEFFS and were punched on cards in a format suitable for use directly as part of an object deck in another program. It was decided that the maximum number of terms necessary for required accuracy is 20 for the asymptotic expansions and 100 for the convergent series.

Computation of the functions $\left\{f_{n}(\xi, \eta), h_{n}(\xi, \eta)\right\}$ is done in program FORMFG using subroutines GCOEF1, GCOEF2, FSGSHS, and GSUMS written in CDC 3600 Fortran. The main program FORMFG pro- vides the input values $\xi$ and $\eta$ and writes the computed functions on a tape. Subroutine FSGSHS performs the actual computation of the functions $\left(f_{n}, h_{n}\right)$ for each value of $(\xi, \eta)$. Subroutine GSUMS computes the functions $\left\{G_{1 n}(\xi, \eta), G_{2 n}(\xi, \eta)\right\}$ for each $(\xi, \eta)$ using the coefficients of $G_{1 n}$ and $G_{2 n}$ as computed in the program GCOEFFS. Subroutines GCOEFl and GCOEF2 set up tables of these coefficients for use by GSUMS.

The first input variable, ISKIP, is used to position the output tape, giving the number of files to be skipped before any writing is done on that tape. Since the functions $\left\{f_{n}, h_{n}\right\}$ are computed for $\xi=-10 .(0.1) 10$. for each $\eta$, it is necessary to read in only the variable $\eta$ (DETA). The program will read in an $\eta$, do the computations and return to read the next $\eta$, continuing until no cards remain. Note that $\eta$ is read in as a double precision variable.

Program listings for the CDC 3600 may be obtained from the authors.

\section{Appendix C. Description and Use of Fortran Programs for Calculation of $\left\{F_{n}, H_{n}\right\}$}

The program INTEGFGH computes the functions $\left\{F_{n}, H_{n}\right\}$ using the formulas (49), (50), (51). The functions $\left\{f_{n}, h_{n}\right\}$ are read from the tape generated by program FORMFG. Results are written on an outtape in the same order as are the $\left\{f_{n}, h_{n}\right\}$.

Input to this program is in two parts: the tape generated by FORMFG, and cards. The first card input variable is KSKIP, which positions the input tape by skipping KSKIP files. This option makes it possible to select the value of $\eta$ for which the computations are to be performed. The upper limit of $\xi(\mathrm{XIF})$ and an approximation to $-\infty$ (AA) are also card input parameters. After each complete integration the input tape is rewound and the next value of KSKIP is read in, followed by the upper limit of $\xi$ and the approximation to $-\infty$. The program continues until no cards remain to be read.

Program listings for the CDC 3600 may be obtained from the authors.

\section{Appendix D. Heat Flux Uniform in $x$}

When the heat flux of the wall in independent of $x$, the stress field will be also. Simple results may be obtained for this case, and these results have been used to corroborate the numerical results described in the text.

Putting $k=0$ in (21) gives the $x$-independent case for the Laplace transforms

$$
\sum(y, s)=\alpha_{1} e^{-y \sqrt{\frac{s}{D}}} \Theta_{1}(s) .
$$

If the outward heat flux $q(t)$ has Laplace transform 
$Q(s)$, we have

$$
Q(s)=-K \sqrt{\frac{s}{D}} \Theta_{1}(s),
$$

so

$$
\sum(y, s)=\frac{\alpha_{1} e}{-K \sqrt{\frac{s}{D}}} Q(s) .
$$

Using the convolution theorem for Laplace transforms, we may obtain the following formula:

$$
\sigma(y, t)=-2 \sqrt{\frac{t}{\pi}} A \int_{0}^{1} d p q\left(t\left(1-p^{2}\right)\right) e^{-\frac{n^{2}}{P^{2}}}, \quad \text { (D2) }
$$

where

$$
A=\frac{\sqrt{D}}{K} \alpha_{1}
$$

A useful relation can be derived for the wall stress $\sigma(0, t)$ in terms of the wall temperature $\mathrm{T}(0, t)$ only, independent of the heat flux history. Setting $y=0$ in (D1) leads to the relation

$$
\sigma(0, t)=\alpha_{1} T(0, t) .
$$

The relations (D2) and (D4) are preserved by numerical tests of (46). 


\section{Publications of the National Bureau of Standards*}

\section{Selected Abstracts}

Inequalities for the permanental minors of non-negative matrices, R. A. Brualdi and M. Newman, Can. J. Math. 18, 608-615 (1966).

It is shown that if $A$ is an $n \times n$ non-negative substochastic matrix then the $r^{\text {th }}$ permanental compound of $A$ is also substochastic. If in addition $A$ is doubly stochastic, then it is shown that the sum of all principal permanental minors of order $r$ does not exceed $\left(\begin{array}{c}n-1 \\ r\end{array}\right)+\left(\begin{array}{c}n-1 \\ r-1\end{array}\right) \operatorname{per}(\mathrm{A})$, with equality if and only if $A$ is the identity matrix.

Real two-dimensional representations of the free product of two finite cyclic groups, J. Lehner and M. Newman, Proc. Camb. Phil. Soc. 62, 135-141 (1966).

All real discrete representations of the free product of two finite cyclic groups by a group of linear fractional transformations are determined.

Congruence subgroups of positive genus of the modular group, M. Newman and M. Knopp, Ill. J. Math. 9, No. 4, 577-583 (Nov. 1965).

Let $\Gamma(n)$ be the principal congruence subgroup of $\Gamma$ of level $n, \Gamma_{n}$ the subgroup of $\Gamma$ generated by $\Gamma(n)$ and $S=\left(\begin{array}{ll}1 & 1 \\ 0 & 1\end{array}\right)$, and $\Gamma_{0}(n)$ the subgroup of $\Gamma$ consisting of all elements $\left(\begin{array}{ll}a & b \\ c & d\end{array}\right)$ of $\Gamma$ such that $c \equiv 0(\bmod n)$. Then it is proved that if $G$ is a subgroup of $\Gamma$ containing $\Gamma_{n}$, then either $G=\Gamma_{\text {or }} G \subset \Gamma_{0}(d), d \mid n, d>1$. This is used to prove that a free congruence subgroup of $\Gamma$ of level $n$ (i.e., a free subgroup of $\Gamma$ containing $\Gamma(n))$ is of positive genus, provided that $(n, 2.3 .5 .7 .13)=1$.

Scattering properties of concentric soot-water spheres for visible and infrared light, R. W. Fenn and H. Oser, J. Appl. Opt. 4, 1504-1509 (Nov. 1965).

Based on the theory by Aden and Kerker, computations of the scattering and absorption properties for concentric spherical waterand-particles have been performed for visible and infrared wave lengths. Computations were performed for size parameter values up to 250 . Results indicate that, for compound particles with a nucleus smaller than about one-tenth of the total diameter of the particle, the optical properties are almost completely determined by the outer shell. Some results of the computations are presented in graphical form for the scattering and absorption efficience factors and the angular scattering functions.

The frequency dependence of the complex dielectric constant is not taken into account in the actual computations: absorption, scattering and total extinction are given for constant index of refraction. The theory does allow to take this dependence into account, however, if one wishes to do so.

\section{Other NBS Publications}

J. Res. NBS 70A (Phys. and Chem.), No. 4 (July-Aug. 1966), $\$ 1.00$.

Elastic constants of synthetic single crystal corundum. W. E. Tefft. Phase equilibria as related to crystal structure in the system niobium pentoxide-tungsten trioxide. R. S. Roth and J. L. Waring.

Properties of aqueous mixtures of pure salts. Thermodynamics of the ternary system: water-calcium chloride-magnesium chloride at $25^{\circ} \mathrm{C}$. R. A. Robinson and V. E. Bower.

Properties of aqueous mixtures of pure salts. Thermodynamics of the ternary system: water-sodium chloride-calcium chloride at $25^{\circ} \mathrm{C}$. R. A. Robinson and V. E. Bower.
Use of the consistency check in the vector verification method. A. D. Mighell, B. T. Gorres, and R. A. Jacobson.

Self-reversal in the spectral lines of uranium. D. D. Laun.

Oscillator strengths for ultraviolet lines of Fe I. C. H. Corliss and B. Warner.

J. Res. NBS 70A (Phys. and Chem.), No. 5 (Sept.-Oct. 1966), $\$ 1.00$.

Orientation of calcium molybdate $\left(\mathrm{CaMoO}_{4}\right)$ and other single crystals having the scheelite structure, E. N. Farabaugh, H. S. Peiser, and J. B. Wachtman, Jr.

Crystal structure of $\mathrm{BaGe}\left[\mathrm{Ge}_{3} \mathrm{O}_{9}\right]$ and its relation to benitoite. C. Robbins, A. Perloff, and S. Block.

A rotating cylinder method for measuring normal spectral emittance of ceramic oxide specimens from 1200 to $1600{ }^{\circ} \mathrm{K}$. H. E. Clark and D. G. Moore.

Electron absorption spectrum of cobalt(II)-doped trisphenanthrolinezinc nitrate dihydrate. C. W. Reimann.

Procedures for homogeneous anionic polymerization. L. J. Fetters. The configurations $4 d^{n}+4 d^{n-1} 5 s$ in doubly ionized palladium group. Y. Shadmi.

J. Res. NBS 70C (Engr. and Instr.), No. 4 (Oct.-Dec. 1966), 75 cents.

Some techniques for measuring small mutual inductances. D. N. Homan.

Deflection of centrally loaded thin circular elastic plates on equally spaced point supports. A. F. Kirstein, W. H. Pell, R. M. Woolley, and L. J. Davis.

Reproducibility of germanium resistance thermometers at $4.2{ }^{\circ} \mathrm{K}$. M. H. Edlow and H. H. Plumb.

Calibration of vibrating-sample magnetometers. W. E. Case and R. D. Harrington.

Notes on the use of propagation of error formulas. H. H. Ku.

The apparent thermal radiation properties of an isothermal $v$-groove with specularly reflecting walls. R. B. Zipin.

Standard x-ray diffraction powder patterns, H. E. Swanson, M. C. Morris, and E. H. Evans, NBS Mono. 25, Section 4 (June 28, 1966), 55 cents.

Electrical parameters of precision, coaxial, air-dielectric transmission lines, R. E. Nelson and M. R. Coryell, NBS Mono. 96 (June 30, 1966), $\$ 1.25$.

Dimensional metrology. Subject-classified with abstracts, I. H. Fullmer, Misc. Publ. 265 (Aug. 1, 1966), \$3.00.

Periodicals and serials received in the Library of the National Bureau of Standards as of October 1965, N. J. Hopper, NBS Misc. Publ. 274 (July 1, 1966), 50 cents. Supersedes Mono. 57.

Measures for progress. A History of the National Bureau of Standards, R. C. Cochrane, NBS Misc. Publ. 275 (1966), \$5.25.

Cooperation, convertibility, and compatibility among information systems: A literature review, M. M. Henderson, J. S. Moats, M. E. Stevens, and S. M. Newman, NBS Misc. Publ. 276 (June 15, 1966), $\$ 2.00$.

Atomic transition probabilities. Hydrogen through neon, W. L. Wiese, M. W. Smith, and B. M. Glennon, NSRDS-NBS4, Vol. I (May 20, 1966), \$2.50.

The band spectrum of carbon monoxide, P. H. Krupenie, NSRDSNBS5 (July 8, 1966), 70 cents.

Weather Resistance of porcelain enamels. Effect of exposure site and other variables after 7 years, M. A. Rushmer and M. D. Burdick, Bldg. Sci. Series 4 (May 2, 1966), 20 cents.

Interrelations between cement and concrete properties. Part 2. Sulfate expansion, heat of hydration, and autoclave expansion, 
R. L. Blaine, H. T. Arni, and D. N. Evans, NBS Bldg. Sci. Series 5, Pt. 2 (July 1, 1966), 35 cents.

Some properties of the calcium aluminoferrite hydrates, E. T. Carlson, Bldg. Sci. Series 6 (June 1, 1966), 20 cents.

Hosiery lengths and sizes excluding women's, CS46-65 (Dec. 31, 1965), 15 cents. Supersedes CS46-49.

Cast iron soil pipe and fittings, CS188-66 (July 1, 1966), 40 cents. (Supersedes CS188-59).

Southern pine plywood, Comm. Std. CS259-63 (as amended through Feb. 1, 1966) (Nov. 15, 1963), 15 cents.

Expanded vinyl fabrics for furniture upholstery use, Comm. Std. CS273-65 (Dec. 31, 1965), 10 cents.

TFE-Fluorocarbon (polytetrofluoroethylene) resin sintered thin coatings for dry film lubrication, CS274-66 (Jan. 20, 1966), 10 cents.

Quarterly radio noise data. December, January, February 1964-65, W. Q. Crichlow, R. T. Disney, and M. A. Jenkins, Tech. Note 18-25 (Mar. 14, 1966), 40 cents. (Formerly Central Radio Propagation Laboratory of the National Bureau of Standards, now Environmental Science Services Administration, Boulder, Colo.)

Quarterly radio noise data March, April, May 1965, W. Q. Crichlow, R. T. Disney, and M. A. Jenkins, NBS Tech. Note 18-26 (May 2, 1966), 45 cents. (Formerly the Central Radio Propagation Laboratory of the National Bureau of Standards, now the Environmental Science Services Administration, Boulder, Colo.)

Transistorized building blocks for data instrumentation, P. G. Stein, NBS Tech. Note 268 (May 28, 1966), 60 cents.

Selected values of chemical thermodynamic properties. Part 2. Tables for the elements twenty-three through thirty-two in the standard order of arrangement, D. D. Wagman, W. H. Evans, I. Halow, V. B. Parker, S. M. Bailey, and R. H. Schumm, NBS Tech. Note 270-2 (May 6, 1966), 40 cents.

Analytical mass spectrometry section: instrumentation and procedures for isotopic analysis, ed. W. R. Shields, Tech. Note 277 (July 25, 1966), 60 cents.

Spark source mass spectrograph program July 1964 to June 1965, P. J. Paulsen and P. E. Branch, NBS Tech. Note 286 (Apr. 15, 1966), 25 cents.

Measurement philosophy of the pilot program for mass calibration, P. E. Pontius, NBS Tech. Note 288 (May 6, 1966), 30 cents.

Status report, National Standard Reference Data System April 1966, ed. E. L. Brady, NBS Tech. Note 289 (June 1, 1966), 50 cents.

Information handling in the National Standard Reference Data System, F. L. Alt, NBS Tech. Note 290 (July 1, 1966), 25 cents.

A bibliography on ion-molecule reactions. January 1900 to March 1966, F. N. Harllee, H. M. Rosenstock, and J. T. Herron, NBS Tech. Note 291 (June 28, 1966), 30 cents.

Some properties of the eigenfunctions and eigenvalues introduced by Bethe for the linear chain of atoms, H. Unruh, Jr., NBS Tech. 328 (Apr. 19, 1966), 25 cents.

The viscosity and thermal conductivity coefficients of dilute argon between 100 and $2000{ }^{\circ} \mathrm{K}, \mathrm{H}$. J. M. Hanley, NBS Tech. Note 333 (March 11, 1966), 25 cents.

An introduction to sampled data and switching logic, T. L. Davis, NBS Tech. Note 334 (Apr. 1, 1966), 40 cents. (Formerly Central Radio Propagation Laboratory of the National Bureau of Standards, now Environmental Science Services Administration, Boulder, Colo.)

Zonal harmonics in low frequency terrestrial radio wave propagation, J. R. Johler, NBS Tech. Note 335 (Apr. 13, 1966), 25 cents. (Formerly the Central Radio Propagation Laboratory of the National Bureau of Standards, now the Environmental Science Services Administration, Boulder, Colo.)

Calculation of the admittance of a parallel plate capacitor containing a toroid-shaped sample, E. G. Johnson, Jr., NBS Tech. Note 336 (Apr. 21, 1966), 30 cents.

Advances in ionospheric mapping by numerical methods, W. B. Jones, R. P. Graham, and M. Leftin, NBS Tech. Note 337 (May 12, 1966), 45 cents. (Formerly the Central Radio Propagation Laboratory of the National Bureau of Standards, now the Environmental Science Services Administration, Boulder, Colo.)

Acid-base behavior in methanol-water solvents, R. G. Bates and R. A. Robinson (Proc. Intern. Symp. Electrochemical Society, Toronto, Canada, May 4-6, 1964), Book, Chemical Physics of Ionic Solution, ch. 12, pp. 211-235 (John Wiley and Sons, Inc., New York, N.Y., 1966).
Combustion and reaction calorimetry of several compounds of interest in a light element program, G. T. Armstrong (Proc. 3d Meeting of the ICRPG Working Group on Thermochemistry, El Segundo, Calif., Mar. 17-18, 1965), Chemical Propulsion Information Agency I, No. 82 (U), 81-88 (July 1965).

Composition, work and interrelation of international and national organization engaged in the standardization of dental materials and therapeutic agents, G. C. Paffenbarger and M. Kumpula, Intern. Dent. J. 15, No. 4, 571-587 (Dec. 1965).

Crystal imperfections in magnesium fluoride, D. J. Barber, J. Appl. Phys. 36, No. 10, 3342-3349 (Oct. 1965).

Dental application of polymers: a review, G. M. Brauer, J. Am. Dental Assoc. 72, 1151-1158 (May 1966).

Dislocations and stacking faults in rutile crystals grown by flamefusion methods, D. J. Barber and E. N. Farabaugh, J. Appl. Phys. 36, No. 9, 2803-2806 (Sept. 1965).

Effect of reactions with the atmosphere during fatigue of metals, J. A. Bennett (Proc. Sagamore Conf. Fatigue, Sagamore, New York, Aug. 15, 1963), Book, Fatigue: An Interdisciplinary Approach, pp. 209-227 (Syracuse University Press, Syracuse, N.Y., 1964).

Electrometric method of $\mathrm{pH}$ determination, R. G. Bates, Book, Standard Methods of Chemical Analysis, 6th edition, IIIA. Instrumental Analysis, ed. F. J. Welcher, ch. 26, pp. 521-532 (D. VanNostrand Co., Inc., Princeton, N.J., 1966).

Field-ion microscopy of ruthenium at $77^{\circ} \mathrm{K}$, A. J. Melmed and R. Klein, J. Less-Common Metals 10, 225-228 (1966).

Growth of large sodium chloride crystals from solution for colorcenter studies, P. M. Gruzensky, J. Chem. Phys. 43, No. 11, 3807-3810 (Dec. 1965).

Kinetics of desorption of the beta-nitrogen states chemisorbed on tungsten, T. E. Madey and J. T. Yates, Jr., J. Chem. Phys. 44, No. 4, 1675-1684 (Feb. 15, 1966).

Melting, flow, and thermal expansion characteristics of some dental and commercial waxes, M. Ohashi and G. C. Paffenbarger, J. Am. Dental Assoc. 72, 1141-1150 (May 1966).

Photoionization mass spectrometry of NO, R. M. Reese and H. M. Rosenstock, J. Chem. Phys. 44, No. 5, 2007-2009 (Mar. 1, 1966). Recrystallization of anodic alumina films, D. J. Barber, J. Electrochem. Soc. 112, No. 11, 1143-1145 (Nov. 1965).

Rubber and rubber products, M. Tryon and E. Horowitz, Book, Standard Methods of Chemical Analysis, 6th Edition, IIIB. Instrumental Analysis, ed. F. J. Welcher, ch. 59, pp. 1664-1763 (D. VanNorstrand Co., Inc., Princeton, N.J., 1966).

The concentration dependence of the sedimentation coefficient of polystyrene in dilute solution, I. H. Billick, Preprint American Chem. Soc. 5, No. 2, 855-860 (1964).

The reaction between $\mathrm{O}\left({ }^{3} \mathrm{P}\right)$ and condensed olefins below $100{ }^{\circ} \mathrm{K}$, A. N. Hughes, M. D. Scheer, and R. Klein, J. Chem. Phys. 70, No. 3, 798-805 (Mar. 1966).

Titrimetric and equilibrium studies using indicators related to Nile Blue A, M. M. Davis and H. B. Hetzer, Anal. Chem. 38, 451-461 (Mar. 1966).

ADI auxiliary publications program, R. W. Zimmerer, IEEE Trans. Microwave Theory Tech. MTT-13, No. 6, 883-884 (Nov. 1965). A precision pulse-operated electronic phase shifter and frequency translator, J. Barnes and A. Wainwright, Proc. IEEE 53, No. 12, 2143-2144 (Dec. 1965).

Can infrared improve visibility through fog? A. Ashley and C. A. Douglas, Illum. Engr. 61, No. 4, 243-250 (Apr. 1966).

Condensate collection as a measuring technique for studying the cooling capacity of air-conditioning units, P. R. Achenbach and J. C. Davis (Proc. XI Intern. Congress of Refrigeration, Munich Germany, 1963), Book, Progress in Refrigeration Science and Technology II, 1281-1286 (Pergamon Press, Inc., New York, N.Y., 1963).

Cryogenic coil for megajoule energy storage, V. Arp, Proc. Intern. Symp. Magnet Technology, ed. H. Brechna and H. S. Gordon, pp. 625-629 (U.S. Atomic Energy Commission, 1965).

Design considerations for a Kossel microdiffraction camera, D. L. Vieth and H. Yakowitz, Rev. Sci. Instr. 37, No. 2, 206-209 (Feb. 1966).

Heating performance of air-to-air heat pumps at two Air Force housing projects, P. R. Achenbach, C. W. Phillips, and W. T. Smith, ASHRAE J. 70, 390-407 (1964). 
Kinematic locator for crystal alignment, B. G. Simson and R. D. Deslattes, Rev. Sci. Instr. 37, No. 3, 300-301 (Mar. 1966).

Laboratory study of the effect of solar radiation on cooling load of stationary refrigerated vehicles, P. R. Achenbach and C. W. Phillips (Proc. XI Intern. Congress of Refrigeration, Munich, Germany, 1963), Book, Progress in Refrigeration Science and Technology III, 1631-1635 (Pergamon Press Inc., New York, N.Y., 1963).

Measuring the cooling load of refrigerated vehicles by free evaporation of liquid nitrogen, P. R. Achenbach, C. W. Phillips, and R. W. Penney, Suppl. Bull. Intern. Inst. Refrigeration, Commission VII, 3, 115-124 (1965).

Thermodynamic property computations for systems analysis, J. G. Hust and R. B. Stewart, ASHRAE J., pp. 64-68 (Feb. 1966).

Infrared reflectance of frost, H. J. Keegan and V. R. Weidner, J. Opt. Soc. Am. Letter 56, No. 4, 523-524(Apr. 1966).

Lightness change of grays induced by change in reflectance of gray background, H. Takasaki, J. Opt. Soc. Am. 56, No. 4, 504-509 (Apr. 1966).

Thoughts on weights and measures, M. W. Jensen, Soap and Chemical Specialties VLII, No. 4, 99 (Apr. 1966).

Analysis of the spectrum of neutral erbium (Er I), N. Spector, J. Opt. Soc. Am. 56, No. 3, 341-349 (Mar. 1966).

Critical configurational entropy at glass transformation, S. S. Chang, A. B. Bestul, and J. A. Horman, Proc. VII Intern. Conf. Glass, Brussels, Belgium, 1965, pp. 26.1-26.15 (Gordon \& Breach, New York, N.Y., 1966).

ESR measurement of metastable atomic nitrogen in helium-nitrogen afterglows, K. M. Evenson and H. E. Radford, Phys. Rev. Letters 15, No. 24, 916-917 (Dec. 1965).

Excitation of molecular rotation by slow electrons II, S. Geltman and K. Takayanagi, Phys. Rev. 143, No. 1, 25-30 (Mar. 4, 1966).

Field emission ultramicrometer, R. D. Young, Rev. Sci. Instr. 37, No. 3, 275-278 (Mar. 1966).

Microscopic visualization of dose distributions, W. L. McLaughlin, Intern. J. Appl. Radiation Isotopes 1 7, 85-96 (1966).

Multiple scattering corrections for proton range measurements, M. J. Berger and S. M. Seltzer, Natl. Acad. Sci.-Natl. Res. Council Publ. 1133, \# 5. Studies in Penetration of Charged Particles in Matter. Nuclear Science Series Report 39, pp. 69-98 (1964).

Nuclear giant quadrupole resonance, R. Ligensa, W. Greiner, and M. Danos, Phys. Rev. Letters 16, No. 9, 364-367 (Feb. 28, 1966).

Nucleation in polymers, F. Gornick and J. D. Hoffman, Ind. Engr. Chem. 58, No. 2, 41-53 (Feb. 1966).

Possible importance of internal excitation in ion-molecule reactions in the $F$ region, L. Thomas and R. B. Norton, J. Geophys. Res. 71, No. 1, 227-230 (Jan. 1, 1966).

Results of some recent transport calculations for electrons and bremsstrahlung, M. J. Berger and S. M. Seltzer, (Proc. 2d Symp. Protection Against Radiations in Space, Gatlinburg, Tenn., Oct. 12-14, 1964, ed. A. Reetz, Jr.), Natl. Aeronaut. Space Admin. Spec. Publ. 71, pp. 437-448 (1965).

Spin independence, W spin, parity, and SU (6) symmetry, H. J. Lipkin and S. Meshkov, Phys. Rev. 143, No. 4, 1269-1274 (Mar. $25,1966)$

A quick, direct method for the determination of activation energy from thermogravimetric data, J. H. Flynn and L. A. Wall, Polymer Letters, 4, Pt. B, No. 5, 323-328 (May 1966).

A standard reference material for Mossbauer spectrometry of iron and its compounds, J. J. Spijkerman, F. C. Ruegg, and J. R. DeVoe, Technical Reports Series 50, Applications of the Mossbauer Effect in Chemistry and Solid-State Physics, pp. 254-259 (International Atomic Energy Agency, Vienna, Austria, 1966).

Action of zinc dust and sodium iodide in $N, N$-dimethylformamide on contiguous, secondary sulfonyloxy groups: a simple method for introducing nonterminal unsaturation, R. S. Tipson and A. Cohen, Carbohydrate Res. 1, No. 4, 338-340 (1965).

Approximate eigenfunctions of the Liouville operator in classical many-body systems, R. Zwanzig, Phys. Rev. 144, No. 1, 170-177 (Apr. 8, 1966).

Crystal growth of bone mineral, W. E. Brown, Clin. Orthopaed. 44, 205-219 (1966).

Infra-red spectra of hydroxyapatite, octacalcium phosphate and pyrolysed octacalcium phosphate, B. O. Fowler, E. C. Moreno, and W. E. Brown, Arch. Oral. Biol. 11, 477-492 (1966).

Phase rule considerations and the solubility of tooth enamel, W. E.
Brown and B. M. Wallace, Ann. N.Y. Acad. Sci. 131, Art. 2, 690-693 (Sept. 30, 1965).

Preparation of inososes from their phenylhydrazones by use of a cation-exchange resin; separation of certain phenylhydraxones from phenylosazones, A. J. Fatiadi, Carbohydrate Res. 1, No. 6, 489-491 (1966).

Pyrolysis of vinyl and vinylidene fluoride polymers: Influence of prior gamma-irradiation, L. A. Wall, S. Straus, and R. E. Florin, J. Polymer Sci. 4, Pt. A-1, 349-365 (1966).

Random-walk model of adsorption of a chain-polymer molecule on a long rigid-rod molecule, R. J. Rubin, J. Chem. Phys. 44, No. 5, 2130-2138 (Mar. 1, 1966).

Rodlike behavior of $\operatorname{poly}(n$-butyl)isocyanate from dielectric measurements, H. Yu, A. J. Bur, and L. J. Fetters, J. Chem. Phys. 44, No. 7, 2568-2576 (Apr. 1, 1966).

Soft tissue response to implants of gallium alloys and silver amalgam alloys, H. W. Lyon, R. M. Waterstrat, and G. C. Paffenbarger, J. Am. Dental Assoc. 72, No. 3, 659-664 (Mar. 1966).

A statistical model of flicker noise, J. A. Barnes and D. W. Allan, Proc. IEEE 54, No. 2, 176-178 (Feb. 1966).

An automatic ellipsometer. Automatic polarimetry by means of an ADP polarization modulator III, H. Takasaki, Appl. Opt. 5, No. 5, 759-764 (May 1966).

An intercomparison of atomic standards, R. Beehler, D. Halford, R. Harrach, D. Allan, D. Glaze, C. Snider, J. Barnes, R. Vessot, H. Peters, J. Vanier, L. Cutler, and L. Bodily, Proc. IEEE 54, No, 2, 301-302 (Feb. 1966).

Bone-air cancellation, E. L. Smith, H. S. Bowman, P. G. Weissler, and R. K. Cook, Bull. Lab. Electroacoustique, No. 9, 45-50 (Apr. 1966).

Convenient safety cutoff device for water cooled equipment, J. J. Ritter and T. D. Coyle, Rev. Sci. Instr. 37, No. 4, 523 (Apr. 1966). Study suggests value of shared computers, A. E. Rikli, S. I. Allen, and S. N. Alexander, Mod. Hosp. 106, No. 5, 100-108 (May 1966).

The NBS-A time scale-its generation and dissemination, J. A. Barnes, D. H. Andrews, and D. W. Allen, IEEE Trans. Instr. Meas. IM- 14, 228-232 (Dec. 1965).

Absolute determination of refractive indices of gases at 47.7 gigahertz, A. C. Newell and R. C. Baird, J. Appl. Phys. 36, No. 12, 3751-3759 (Dec. 1965).

International comparison of measurements at high frequencies, M. C. Selby, IEEE Spectrum 3, No. 1, 89-98 (Jan. 1966).

LF-VLF frequency and time services of NBS, D. H. Andrews, IEEE Trans. Instr. Meas. IM-14, No. 4, 233-237 (Dec. 1965).

The system of electromagnetic quantities at $30 \mathrm{kHz}$ to $\mathrm{GHz}, \mathrm{M}$. C. Selby, Metrologia 2, No. 1, 37-45 (Jan. 1966).

The system of electromagnetic quantities at frequencies above $1 \mathrm{GHz}, \mathrm{R}$. W. Beatty, Metrologia 2, No. 1, 46-54 (Jan. 1966).

The "volt standard" moves to Gaithersburg, Maryland, W. J. Hamer, J. Wash. Acad. Sci. 56, 101-108 (May 1966).

A nomogram for determining azimuth and horizontal trace velocity from tripartite measurements, H. Matheson, Earthquake Notes XXXVII, No. 1, 33-37 (Mar. 1966).

Correction in the laboratory measurement of the rate constant for $\mathrm{N}_{\frac{1}{2}}+\mathrm{O}_{2} \rightarrow \mathrm{N}_{2}+\mathrm{O}_{2}^{\frac{1}{2}}$ at $300{ }^{\circ} \mathrm{K}$, F. C. Fehsenfeld, A. L. Schmeltekopf, and E. E. Ferguson, Planetary Space Sci. 13, 919-920 (Sept. 1965).

Electromagnetic wave propagation and relativistic damping effects in a uniformly magnetized electron-positron gas, L. A. Steinert, Il Nuovo Cimento 40, No. 10, 345-374 (Dec. 1965).

Energy gap of superconducting tin films in a magnetic field, R. S. Collier and R. A. Kamper, Phys. Rev. 143, No. 1, 323-328 (Oct. 1966).

Extended dislocation nodes in a silver-tin alloy, L. K. Ives and A. W. Ruff, Jr., J. Appl. Phys. 37, No. 4, 1831-1837 (Mar 15, 1966).

Force fields for group IV tetrafluorides and group $\mathrm{V}$ trifluorides, I. W. Levin and S. Abramowitz, J. Chem. Phys. 44, No. 7, 25622567 (Apr. 1, 1966).

Longitudinal magnetoresistance of copper, R. L. Powell, Low Temp. Phys. LT-9, Pt. B, 732-735 (1965).

On the definition of the stacking-fault energy in binary alloys, R. deWit and R. E. Howard, Acta. Met. 14, No. 3, 431-433 (1966). Possible nuclear contribution to thermal expansion, E. C. Hirschkoff and N. N. Wolcott, Proc. Phys. Soc. 86, No. 6, 1372 (1965). Possible observation of $\operatorname{In}^{115}$ nuclear electric hexadecapole transi- 
tions, R. J. Mahler, L. W. James, and W. H. Tantilla, Phys. Rev. Letters 16, No. 7, 259-261 (Feb. 14, 1966).

Random-walk method for calculating correlation factors: Tracer diffusion by divacancy and impurity-vacancy pairs in cubic crystals, R. E. Howard, Phys. Rev. 144, No. 2, 650-651 (Apr. 15, 1966).

Relaxations in polyethylene: Orientation of the lamellar crystals, R. K. Eby and J. P. Colson, J. Acoust. Soc. Am. 39, No. 3, 506-510 (Mar. 19, 1966).

Role of surface diffusion in stabilizing the surface of a solid growing from solution or vapor, S. R. Coriell and R. L. Parker, J. Appl. Phys. 37, No. 4, 1548-1550 (Mar. 15, 1966).

The optical constants of some oxide glasses in the strong absorption region, G. W. Cleek, Appl. Opt. 5, No. 5, 771-775 (May 1966).

Three-body photodisintegration of $\mathrm{He}^{3}, \mathrm{H}$. M. Gerstenberg and J. S. O'Connell, Phys. Rev. 144, No. 3, 834-838 (Apr. 22, 1966).

Use of ellipsometry in the study of corrosion, J. Kruger, Corrosion 22, No. 4, 88-97 (Apr. 1966).

Wave propagation in a three-element linear spring and dashpot model filament, J. C. Smith, J. Appl. Phys. 37, No. 4, 1697-1704 (Mar. 15, 1966).

Perturbation theorems for waveguide junction, with applications, D. M. Kerns and W. T. Grandy, IEEE Trans. Microwave Theor. Tech. MTT-14, No. 12, 85-92 (Feb. 1966).

The effect of atmospheric noise on the probability of error for an NCFSK system, A. M. Conda, IEEE Trans. Commun. Technol. CT-13, No. 3, 280-284 (Sept. 1965).

Acids, bases, and buffers, R. G. Bates, (Proc. Symp. Current Concepts of Acid-Base Measurements, New York Academy of Sciences, New York, N.Y., Nov. 23, 1964), Ann. N.Y. Acad. Sci. 133 , Art. 1, 25-33 (1966).

Comparative strengths of aliphatic acids and some other carboxylic acids in benzene at $25^{\circ}$, M. M. Davis and M. Paabo, J. Organic Chem. 31, 1804-1810 (1966).

Crystal chemistry of calcium phosphates, W. E. Brown, Proc. 1964 Technical Session on Cane Sugar Refining Research, New Orleans, Louisiana, Nov. 9-10, 1964, pp. 26-34 (Agriculture Research Service, New Orleans, Louisiana, Mar. 1966).

Emission spectrometry, M. Margoshes and B. F. Scribner, Anal. Chem. 38, No. 5, 297R-310R (Apr. 1966).

Equilibrium pressures of oxygen over oxides of lead at various temperatures, E. M. Otto, J. Electrochem. Soc. 113, No. 6, 525-527 (June 1966)

Liquid immiscibility in the rare earth oxide-boric oxide systems, E. M. Levin, Phys. Chem. Glasses 7, No. 3, 90-93 (June 1966).

Low-frequency motions and barrier to rotation in phosphonium iodide, J. J. Rush, J. Chem. Phys. 44, No. 4, 1722-1723 (Feb. 15, 1966).

Matrix-isolation study of the infrared and ultraviolet spectra of the free radical CNN, D. E. Milligan and M. E. Jacox, J. Chem. Phys. 44, No. 8, 2850-2856 (Apr. 15, 1966).

Microwave spectra of alkali hydroxides: evidence for linearity of $\mathrm{CsOH}$ and $\mathrm{KOH}$, R. L. Kuczkowski, D. R. Lide, Jr., and L. C. Krisher, J. Chem. Phys. 44, No. 8, 3131-3132 (Apr. 15, 1966).

Neutron and infrared spectra of $\mathrm{HCrO}_{2}$ and $\mathrm{DCrO}_{2}$, J. J. Rush and J. R. Ferraro, J. Chem. Phys. 44, No. 6, 2496-2498 (Mar. 15, 1966).

Structure of cubic ammonium fluosilicate: neutron-diffraction and neutron-inelastic scattering studies, E. O. Schlemper, W. C. Hamilton, and J. J. Rush, J. Chem. Phys. 44, No. 6, 2499-2502 (Mar. 15, 1966).

Application of sulfur coatings to integrating spheres, S. T. Dunn, Appl. Opt. 4, No. 7, 877 (July 1965).

Simple contact type temperature controller, L. A. Marzetta, Rev. Sci. Instr. Note 37, No. 6, 789 (June 1966).

Some statistical properties of pulses from photomultipliers, M. Gadsden, Appl. Opt. 4, No. 11, 1446-1452 (Nov. 1965).

Use of an auxiliary sphere with a spectrophotometer to obtain absolute reflectance, D. G. Goebel, B. P. Caldwell, and H. K. Hammond, J. Opt. Soc. Am. 56, No. 6, 783-788 (June 1966).

Anniversaries in 1965 of interest to statisticians, C. Eisenhart, Am. Stat. 19, No. 5, 21-29 (Dec. 1965).

The assumptions underlying the analysis of variance, C. Eisenhart, (Spanish Translation by Jose Otaduy), Book, Sobre el Analisis de la Variancia, pp. 1-24 (Comision de Educacion Estadistica del Instituto Interamerican de Estadistica, Rosario, Argentina, 1953).
Debye relaxation in symmetric-top-foreign-gas mixtures; temperature dependence of collision cross sections, L. Frenkel, S. J. Kryder, and A. A. Maryott, J. Chem. Phys. 44, No. 7, 2610-2619 (Apr. 1, 1966).

Demountable high power source for soft x-ray region, R. D. Deslattes and B. G. Simson, Rev. Sci. Instr. 37, No. 6, 753-754 (June 1966).

EPR spectrum of gas-phase sulfur atoms, R. L. Brown, J. Chem. Phys. 44, No. 7, 2827-2828 (Apr. 1, 1966).

Gas density stabilizer for flow proportional counters, R. D. Deslattes, B. G. Simson, and R. E. LaVilla, Rev. Sci. Instr. 37, No. 5, 596599 (May 1966).

Inelastic scattering cross sections for $20-\mathrm{keV}$ electrons in $\mathrm{Al}, \mathrm{Be}$, and polystyrene, N. Swanson and C. J. Powell, Phys. Rev. 145, No. 1, 195-208 (May 6, 1966).

Influence of an external magnetic field on nuclear resonance in ferromagnetic materials, L. H. Bennett, J. Appl. Phys. 37, No. 3, 1242-1243 (Mar. 1, 1966).

Measurement of absolute wavelength stability of lasers, K. D. Mielenz, R. B. Stephens, K. E. Gillilland, and K. F. Neffien, J. Opt. Soc. Am. 56, No. 2, 156-162 (Feb. 1966).

Measurement of the $6 \dot{3} 3-\mathrm{nm}$ wavelength of helium-neon lasers, K. D. Mielenz, R. B. Stephens, K. E. Gillilland, K. F. Nefflen, and R. B. Zipin, Appl. Phys. Letters 7, No. 10, 277-279 (Nov. 1965). Methods of determining coriolis zeta constants, S. Abramowitz and I. W. Levin, J. Mol. Spectry. 19, No. 4, 461-462 (Apr. 1966).

Plasmon damping metals, B. W. Ninham, C. J. Powell, and N. Swanson, Phys. Rev. 145, No. 1, 209-217 (May 6, 1966).

Polycrystalline spin wave theory of ferro-magnetic resonance compared with the tilting experiment, A. S. Risley, E. G. Johnson, and H. E. Bussey, J. Appl. Phys. 3 7, No. 2, 656-668 (Feb. 1966).

Shock wave propagation in cubic lattices, D. H. Tsai and C. W. Beckett, J. Geophys. Res. 71, No. 10, 2601-2608 (May 15, 1966).

Some applications of the wave front shearing interferometer, J. B. Saunders, Japanese J. Appl. Phys. Suppl. I, 4, 99-105 (1965).

Superconducting behavior of indium-lead alloys, S. Gygax, J. L. Olsen, and R. H. Kropschot (Proc. IXth Intern. Conf. Low Temperature Physics, Columbus, Ohio, Aug. 31-Sept. 4, 1964), Book, Low Temperature Physics LT9, Pt. A, ed. J. G. Daunt, D. O. Edwards, F. J. Milford, and M. Yaqub, pp. 587-590 (Plenum Press Inc., New York, N.Y., 1965).

Superconductivity in ceramic, mixed titanates, H. P. R. Frederikse, J. F. Schooley, W. R. Thurber, E. Pfeiffer, and W. R. Hosler, Phys. Rev. Letters 16, No. 13, 579-581 (Mar. 28, 1966).

The measurement of homogeneity of optical materials in the visible and infrared, F. W. Rosberry, Appl. Opt. 5, No. 6, 961-966 (June 1966).

Two-state model for the free volume of vitreous $\mathrm{B}_{2} \mathrm{O}_{3}, \mathrm{P}$. B. Macedo, W. Capps, and T. A. Litovitz, J. Chem. Phys. 44, No. 9, 3357-3364 (May 1, 1966).

A survey of the thermodynamic data on heavier elements and their compounds: high-temperature enthalpy and vaporization equilibria, T. B. Douglas, Proc. 3d Meeting Interagency Chemical Rocket Propulsion Group, Working Group on Thermochemistry, El Segundo, Calif., Mar. 17-18, 1965, I, No. 82U, 5-16 (Chemistry Propulsion Information Agency, Silver Spring, Md., July 1965). Activation-analysis program and facilities at the National Bureau of Standards, J. R. DeVoe and G. W. Smith, Proc. 1965 Intern. Conf. Modern Trends in Activation Analysis, Texas A \& M University, College Station, Texas, pp. 225-229 (Apr. 1965). Additional observations on the electronic spectrum of copper (II) acetate monohydrate, C. W. Reimann, G. F. Kokoszka, and G. Gordon, J. Inorg. Chem. 4, No. 7, 1082-1084 (July 1965).

Density and specific gravity, J. K. Taylor, Encyclopedia of Industrial Analysis 1, 546-560 (Interscience Publ. Inc., New York, N.Y., 1965).

Determination of trace amounts of tellurium in standard reference materials by neutron-activation analysis, D. A. Becker and G. W. Smith, Proc. 1965 Intern. Conf. Modern Trends in Activation Analysis, Texas A \& M University, College Station, Texas, pp. 230-235 (Apr. 1965).

Electron paramagnetic resonance and nuclear magnetic resonance as analytical tools, T. C. Farrar, (Proc. Conf. Purification of Materials, New York Academy of Sciences), Ann. N.Y. Acad. Sci. 137, 323-334 (Jan. 1966).

Equilibrium pressures of oxygen over $\mathrm{Ag}_{2} \mathrm{O}-\mathrm{Ag}$ at various tempera- 
tūres, E. M. Otto, J. Electrochem. Soc. 113, No. 7, 643-645 (July 1966).

Force fields for some group VI hexafluorides, S. Abramowitz and I. W. Levin, J. Chem. Phys. 44, No. 9, 3353-3356 (Nay 1, 1966).

Formation of crystallites of benzophenone in hydrocarbon glass, R. Keller and D. Breen, J. Chem. Phys. 43, No. 7, 2562-2563 (Oct. 1965).

Franck-Condon factors and the mass spectra of small molecules, H. M. Rosenstock, (Proc. Intern. Mass Spectrometry Conf., ASTM E-14, The Hydrocarbon Research Group and GAMS, Paris, France, Sept. 1964), Adv. Mass Spectrometry 3, 435439 (1966).

Gas-phase radiolysis of cyclopentane. Relative rates of $\mathrm{H}_{2}$-transfer reactions from various hydrocarbons to $\mathrm{C}_{3} \mathrm{H}_{6}^{+}, \mathrm{R}$. D. Doepler and P. Ausloos, J. Chem. Phys. 44, No. 5, 1951-1958 (Mar. 1966).

Infrared spectrum of the free radical $\mathrm{CF}_{3}$ isolated in inert matrices, D. E. Milligan, M. E. Jacox, and J. J. Comeford, J. Chem. Phys. 44, No. 10, 4058-4059 (May 1966).

Ion-molecule reaction in the liquid and solid phase radiolysis of hydrocarbon mixtures, P. Ausloos, A. A. Scala, and S. G. Lias, J. Am. Chem. Soc. 88, 1583-1584 (1966).

Ion-pair process in $\mathrm{CH}_{3} \mathrm{Cl}$ by photoionization, V. H. Dibeler and J. A. Walker, J. Chem. Phys. 43, No. 5, 1842-1843 (Sept. 1965).

Microwave spectrum of perchlorylfluoride, D. R. Lide, Jr., J. Chem Phys. 43, No. 10, 3767-3768 (Nov. 1965).

Nuclear magnetic resonance studies of inorganic fluorides. II. Solvent effects on $\left.\mathrm{J}^{29} \mathrm{Si}^{-19} \mathrm{~F}\right)$ in silicon tetrafluoride, T. D. Coyle, R. B. Johannesen, F. E. Brinckman, and T. C. Farrar, J. Phys Chem. 70, No. 5. 1682-1684 (Mav 1966).

Phase relations between $\mathrm{Cr}_{2} \mathrm{O}_{3}$ and $\mathrm{IrO}_{2}$ in air, C. L. McDaniel and S. J. Schneider, J. Am. Ceramic Soc. 49, No. 5, 285-286 (May 1966).

Photoinoization of propylene at $1236 \AA$. Reactions of $\mathrm{C}_{3} \mathrm{D}_{6}^{+}$with added alkanes, R. Gorden, Jr., R. Doepker, and P. Ausloos, J. Chem. Phys. 44, No. 10, 3733-3740 (May 1966).

Progress report on a test for cleanability, M. D. Burdick, Proc. Procelain Enamel Institute Forum 26, 41-48 (1965).

Progress report on the development of a standardized test for continuity of procelain enamel coatings, M. A. Rushmer, Proc. Porcelain Enamel Institute 27, 49-56 (1965).

Purification of single crystal growth, J. L. Torgesen, Ann. N.Y. Acad. Sci. 137, 30-43 (1966).

Shear relaxation times of simple fluids, R. D. Mountain and R. Zwanzig, J. Chem. Phys. 44, No. 7, 2777-2779 (Apr. 1966).

Silicon-fluorine chemistry. II. Silicon-boron fluorides, P. L. Timms, T. O. Ehlert, J. L. Margrave, F. E. Brinckman, T. C. Farrar, and T. D. Coyle, J. Am. Chem. Soc. 87, No. 17, 3819-3823 (Sept. 1965). Some aspects of the coulomb hole of the ground state of $\mathrm{H}_{3}^{+}$, W. Lester and M. Krauss, J. Chem. Phys. 44, No. 1, 207-212 (Jan. 1966).

Spectrochemical analysis of high-temperature alloys by $s_{p}$ ark excitation in argon and nitrogen, H. C. Dilworth, Am. Soc. Testlitg Mater. Spec. Tech. Publ. 376 (1965).

Standardization of the differential chemical shift for $\mathrm{Fe}^{57}$, J. J Spijkerman, F. C. Ruegg, and J. R. DeVoe (Proc. New England Nuclear Mossbauer Symp., New York, N.Y., Jan. 1964), Book, Mossbauer Effect Methodology, pp. 115-120 (Plenum Press Inc., New York, N.Y., 1965)

The electron paramagnetic resonance spectrum of tetrakis- $t$-butoxyvanadium(IV), G. F. Kokoszka, H. C. Allen, Jr., and G. Gordon, Inorg. Chem. 5, 91-93 (1966).

The microwave spectrum of dinitrogen trioxide, R. L. Kuczkowski, J. Am. Chem. Soc. 87, 5259-5260 (1965).

A cooling system for a laboratory magnet, R. A. Forman and T. McKneely, Appl. Spectry. 20, 189 (May-June 1966).

A large signal IGFET DC source follower, D. P. Stokesberry, Proc. IEEE 54, No. 1, 66 (Jan. 1966).

A method for calibrating volt boxes, with analysis of volt-box selfheating characteristics, R. F. Dziuba and T. M. Souders, IEEE Intern. Conf. Record, Pt. 10, pp. 17 (Mar. 21-25, 1966).

A semi-automatic technique for tuning a reflectometer, M. H. Zanboorie, IEEE Trans. Microwave Theory Tech. MTT-13, No. 5, 709-710 (Sept. 1965).

A simple current generator, J. K. Whittaker, Nuclear Instr. Methods 39, No. 1, 183-184 (Jan. 1966).

A zero-crossing discriminator with picosecond time slewing, J. K. Whittaker, IEEE Trans. Nuclear Sci. NS-13, No. 1, 399-405 (Feb. 1966)
Anomalous conductance behavior in polymers, A. H. Scott (1965 Annual Report Conf. Electrical Insulation), NAS-NRC Publ. 1356 , pp. 98-102 (Natl. Acad. Sci.-Natl. Res. Council, Washington, D.C., 1966).

Apparent negative impedances and their effect on three-terminal dielectric loss measurements, W. P. Harris (1965 Annual Report Conf. Electrical Insulation), NAS-NRC Publ. 1356, pp. 83-86 (Natl. Acad. Sci. - Natl. Res. Council, Washington, D.C., 1966).

Effects of thermal shrinkage on built-up roofing, W. C. Cullen, J. Bldg. Res. Inst. 2, No. 4, 23 (July-Aug. 1965).

Fire test methods for paints, A. F. Robertson, Bldg. Res. pp. 48-52 (July-Aug. 1965).

Flow measurement standardization, T. Filban and M. R. Shafer, Proc. ISA Conf. 1964, 19, Pt. 1, Paper No. 12-2-4-64 (1964).

Guide to dental materials, 1966-1967, G. C. Paffenbarger, J. W. Stanford, M. P. Kumpula, and W. T. Sweeney, Am. Dental Assoc. 3d ed., 188 pages (Chicago, Ill., 1966).

Human engineering with design of a console for the comparison of volt boxes, P. H. Lowrie, Jr., ISA J. pp. 67-71 (July 1965).

International intercomparison of standards for microwave power measurement, G. F. Engen, IEEE Trans. Microwave Theory Tech. MTT-13, No. 5, 713-715 (Sept. 1965)

Measuring the coordinates of a number of points in a complex laboratory-scale model, F. D. Ordway, Rev. Sci. Instr. 36, No. 8, 11561159 (Aug. 1965)

Modular software for on-line handling of nuclear data, J. M. Wyckoff, IEEE Trans. Nuclear Sci. NS-13, No. 1, 199 (Feb. 1966).

National Bureau of Standards offers method to prevent built-up roof splitting failure, W. C. Cullen, Roofing Siding Insulation Mag. 40, No. 4, 28-30 (Apr. 1965)

1965 Meeting of IEC Committee TC45, Progress in Nuclear Instrumentation, L. Costrell, Mag. Std., p. 9 (Jan. 1966).

Roofing research in Guam and Okinawa, W. C. Cullen, Am. Roofer Bldg. Improvement Contractor, pp. 10 (Oct. 1965).

Standards for galvanomagnetic devices, S. Rubin, Solid State Elec tronics 9, 5, 559-566 (May 1966).

Suppression of $60 \mathrm{c} / \mathrm{s}$ pickup when using sensitive DC amplifiers, R. L. Nuttall and D. C. Ginnings, Electron. Design 12, No. 26, pp. 34-35 (Dec. 20, 1965).

Tapered inlets for pipe culverts, discussion and author's closure, J. L. French, J. Hydraulics (Dıv. Am. Soc. Civil Eng.) pp. 286 (May 1965).

The effect of insulation on the durability of a smooth-surfaced builtup roof, W. C. Cullen and W. H. Appleton, Coal Tar Asphalts and Related Mater. 3, 122-124 (Mar. 1965).

The NBS instrumentation for use in the measurement of spectral irradiances of solar simulators, R. Stair and W. E. Schneider, Proc. Intern. Symp. Solar Radiation Simulation, Los Angeles, Calif., Jan. 18-20, 1965, pp. 75-94 (Inst. Environmental Sciences and Am. Soc. Testing and Materials, 1965).

The response of flush diaphragm pressure transducers to thermal gradients, L. Horn, ISA 20th Annual Conf. and Exhibit, Los Angeles, Calif., Oct. 4-7, 1965, 20, Pt. Ill, ISA Preprint No. 13.34-65 (1965).

Thermal insulation in buildings, F. J. Powell, Military Engr. 58, No. 38, 275-276 (July-Aug. 1966).

Voltmeter calibration to $1 \mathrm{GHz}$, M. C. Selby, W. J. Blank, and R. P. Chairton, (Proc. 1965 Wescon Conf., San Francisco, Calif., Aug. 1965), IEEE WESCON Tech. Papers 9, Pt. 6, No. 8.8, 1-12 (1965).

The design of a federal statistical data center, D. Rosenblatt, E Glaser, and M. K. Wood, Statistical Evaluation Report No. 6, Office of Statistical Standards, Bureau of the Budget, Appendix C, pp. 1-19 (Office of the President, Washington, D.C., Dec. 1965).

Color designation and specification, D. B. Judd, Encyclopedia of Industrial Analysis 1, 315 (1966).

Electrical testing in chemical technology, A. H. Scott, Encyclopedia of Chemical Technology, 2d ed., 7, 716-726 (1965).

Measurement of DC dielectric conductance (reciprocal resistance) at elevated temperatures, A. H. Scott, Proc. 6th Electrical Insulation Conf., Sept. 13-16, 1965, pp. 252-254 (1965).

Metrology essential to the space age, A. G. McNish, George Washington University Mag. 1, No. 4, 10-14 (1965).

Progress report for OSA Committee on uniform color scales, D. B. Judd, Proc. Intern. Color Comm., Lucerne, Switzerland, 1965, 1, 399-407 (Mar. 1966). 
Specification and designation of color, D. B. Judd and I. Nimeroff, Treatise Anal. Chem. 36, 2873-2942 (1964).

The calibration of permanent magnet standards, I. L. Cooter, ISA 20th Annual Conf. and Exhibit, Part 1. Measurement Standards and Instrumentation, Los Angeles, Calif., Oct. 4-7, 1965, 20, Pt. 1, ISA Preprint 14.1-3-65 (1965).

The international system of units, A. G. McNish, American Society for Quality Control Annual 1965 Tech. Conf. Trans. Industrial Quality Control 22, No. 9, 465-469 (Mar. 1966).

The nature of measurement, A. G. McNish, Book, Industrial Metrology (Sponsored by the American Society of Tool and Manufacturing Engineers), ch. 1, 4, No. 2, 24-31 (Mar. 1966).

Color appearance, D. B. Judd, Proc. Intern. Color Comm., Lucerne, Switzerland, 1965, 1, 27-51 (Mar. 1966).

Cooler for semiconductor light emitters, lasers and photodetectors, H. K. Kessler, Rev. Sci. Instr. 37, 517-518 (Apr. 1966).

Decays of positive-parity baryon resonances in a broken U(12), H. Harari, D. Horn, M. Kugler, H. J. Lipkin, and S. Meshkov, Phys. Rev. 140, No. 4B, B1003 (Nov. 1965).

Discussion of ASME paper 60-WA-333, November 30, 1960, D. P. Johnson and U. O. Hutton, Book, High Pressure Measurement, ed. A. A. Giardini and E. C. Lloyd, pp. 350-351 (Butterworth, Inc., London, England, 1963).

Effects of space radiation on refractive properties of optical glass, I. H. Malitson, M. J. Dodge, and M. E. Gonshery, Proc. Annual Conf. Photography, Science and Engineering, San Francisco, Calif., May 9-13, 1966, p. 75 (1966).

Elastic constants of single crystal $\mathrm{UO}_{2}$ at $25^{\circ} \mathrm{C}$, J. B. Wachtman, Jr., M. L. Wheat, H. J. Anderson, and J. L. Bates, J. Nuclear Mater. 16, 39-41 (1965).

Electron energy bands in $\mathrm{SrTiO}_{3}$ and $\mathrm{TiO}_{2}$ (theory and experiment), A. K. Kahn, H. P. R. Frederikse, and J. H. Beckerd, (Informal Proc. Bull., Intern. Conf. Materials, Pittsburgh, Pa., 1963), Book, Transition of Metal Compounds, ed. E. R. Schatz, pp. 53-64 (Gordon and Breach Sci. Publ., New York, N.Y., 1964).

Fundamental studies of color vision from 1860 to 1960, D. B. Judd, Proc. Natl. Acad. Sci. 55, No. 6, 1313-1330 (June 1966).

Geomagnetic and solar data, J. V. Lincoln, J. Geophys. Res. 70, No. 13, 3227-3228 (July 1965); 70, No. 15, 3761-3763 (Aug. 1965); 70, No. 17, 4383-4384 (Sept. 1965); 70, No. 19, 4963-4964 (Oct. 1965)

High resolution infrared spectra of cyanogen and cyanogen- ${ }^{15} \mathrm{~N}_{2}$, A. G. Maki, J. Chem. Phys. 43, No. 9, 3193-3199 (Nov. 1965).

Interspecimen comparison of the refractive index of fused silica, I. H. Malitson, J. Opt. Soc. Am. 55, No. 10, 1205 (Oct. 1965).

Intrinsic and lattice-induced distortion of the tetrachlorocuptrate ion, M. Sharnoff and C. W. Reimann, J. Chem. Phys. 43, No. 9, 2993-2996 (Nov. 1965).

Line broadening, W. L. Wiese, Book, Plasma Diagnostic Techniques, ed. R. H. Huddleston and S. L. Leonard, 21, 265-317 (Academic Press Inc., New York, N.Y., 1965).

Magnetic susceptibility of insulating and semiconducting strontium titanate, H. P. R. Frederikse and G. A. Candela, Phys. Rev. 147, No. 2, 583-584 (July 15, 1966).

Magnetoacoustic adsorption and the fermi surface in potassium, H. J. Foster, P. H. Meijer, and E. V. Mielczarek, Phys. Rev. 139, No. 6A, A1849-A1857 (Sept. 1965).

Magnetoresistance of semiconducting $\mathrm{SrTiO}_{3}, \mathrm{H}$. P. Frederikse, W. R. Hosler, and W. Thurber, Phys. Rev. 143, No. 2, 648-651 (Mar. 1966).

Measurements of ion-optical properties of a high resolution spectrometer for electron scattering, S. Penner and J. W. Lightbody, Proc. Intern. Symp. Magnetic Technologies, Stanford Linear Accelerator Center, Stanford Univ., Calif., Sept. 8-10, 1965, pp. 154-163 (Oct. 1965).

Newly observed structure in the photoionization continua of $\mathrm{Kr}$ and Xe below $160 \AA$, K. Codling and R. P. Madden, Appl. Opt. 4, 1431-1434 (Nov. 1965).
Observations of dislocations in ammonium dihydrogen phosphate: production of dislocation-free crystals, R. D. Deslattes, J. L. Torgesen, B. Parketzkin, and A. T. Horton, J. Appl. Phys. 37, No. 2, 541-548 (Feb. 1966).

Observatory reports, spectroscopy, C. E. Moore, Astron. J. 70, No. 9 , 637-639 (Nov. 1965).

Optical absorption of cobalt in manganese fluoride, R. F. Blunt, J. Chem. Phys. 44, No. 6, 2317-2320 (Mar. 15, 1966).

Photon absorption cross section of spherical nuclei, M. G. Huber, H. J. Weber, M. Danos, and W. Greiner, Phys. Rev. Letters 15, No. 12, 529-531 (Sept. 1965)

Photoneutron reactions, E. G. Fuller (Proc. Intern. Conf. Study of Nuclear Structure with Neutrons, Antwerp, Belgium, July 14-23, 1965), Book, Nuclear Structure Study with Neutrons, ed. M. Neve De Mevergnies, P. VanAssche, and J. Vervier, pp. 359-375 (NorthHolland Publ. Co., Amsterdam, The Netherlands, 1966).

Photonuclear reactions, M. Danos and E. G. Fuller, Ann. Rev. Nuclear Sci. 15, 29-66 (1966).

Radiative recombination lifetimes in laser excited silicon, N. N Winogradoff and H. K. Kessler, Appl. Phys. Letters 8, No. 4, 99 (Feb. 1966).

Radiation of sound by earthquakes, R. K. Cook, $5^{\mathrm{e}}$ Cong. Intern. Acoustique, Liege, Belgium 1b, K19 (1965).

Relation of strength of thermally tempered glass to fracture mirror size, M. K. Kerper and T. G. Scuderi, Am. Ceramic Soc. Bull. 44, No. 12, 953-955 (Dec. 1965).

Resolving power related to aberration, F. E. Washer, Photogram metric Eng. XXXII, No. 2, 213-226 (Mar. 1966).

Second breakdown and current distributions in transistors, H. A Schafft and J. C. French, Solid-State Electron. 9, No. 7, 681-688 (July 1966).

Secondary electron trajectories in a Faraday cup magnetic field J. S. Pruitt, Nuclear Instr. Methods 39, 329 (Feb. 1966).

Structure in the photo-ionization continuum of $\mathrm{N}_{2}$ near $500 \AA, \mathrm{K}$. Codling, Astrophys. J. 143, No. 2, 552-558 (Feb. 1966).

Symmetry conditions on jump rates occuring in relaxation times associated with point defect motion, H. S. Peiser and J. B. Wachtman, Jr., J. Phys. Chem. Solids 27, 975 (1966).

Tables of dielectric constants, dipole moments and dielectric relaxation times, F. I. Mopsik, (1964 Digest of Literature on Dielectric Conf. Electrical Insulation), NAS-NRC Publ. 1342, 28, 33-66 (Natl. Acad. Sci.-Natl. Res. Council, Washington, D. C., 1965)

The interaction of radiation with charged particles. I, W. H. Chappell, W. E. Brittin, and S. J. Glass, Il Nuovo Cimento 38, No. 3, 1186-1191 (1965).

The interaction of radiation with charged particles. II. Dispersion relation for transverse modes, S. J. Glass and W. R. Chappel, Il Nuovo Cimento 38, No. 1, 79-88 (1966).

The paramagnetic resonance spectrum of $\mathrm{W}^{5+}$ in rutile $\left(\mathrm{TiO}_{2}\right)$, T. T. Chang, Phys. Rev. 147, No. 1, 264-267 (July 8, 1966).

Atmospheric research and electromagnetic telecommunication, Part I, H. G. Booker and C. G. Little, IEEE Spectrum 2, No. 8, 44-52 (Aug. 1965).

Atmospheric research and electromagnetic telecommunication, Part II, H. G. Booker and C. G. Little, IEEE Spectrum 2, No. 9, 98-103 (Sept. 1965)

*Publications for which a price is indicated are available by purchase from the Superintendent of Documents, U.S. Government Printing Office, Washington, D.C., 20402 (foreign poastage, onefourth additional). The NBS nonperiodical series are also available from the Clearinghouse for Federal Scientific and Technical Information, Springfield, Va., 22151. Reprints from outside journals and the NBS Journal of Research may often be obtained directly from the authors. 